\title{
一种合成 $\beta$-甲酰氟硼吡咯新方法
}

\author{
叶家海* 叶文芳肖承涛陈雨 王光普 张文超
}

(南京理工大学化工学院 南京 210094)

\begin{abstract}
摘要 氟硼吡咯和氮杂氟嗍吡咯分别与草酰氯在 $N, N$-二甲基甲酰胺溶液中发生 Vilsmeier-Haack 反应, 生成相应的 $\beta$ 甲酰氟嗍吡咯和 $\beta$-甲酰氮杂氟嗍吡咯. 该反应分别在室温和 $50{ }^{\circ} \mathrm{C}$ 搅拌条件下顺利实现，并对氟嗍吡咯和氮杂氟嗍吡 咯两种底物都具有较高产率. 此外, 该反应具有原料易得、低污染的优点.
\end{abstract}

关键词＼cjkstart氟硼吡咯; 氮杂氟硼吡咯; $\beta$-甲酰化; Vilsmeier-Haack 反应

\section{A New Approach to the Synthesis of $\beta$-Formyl-boron-dipyrromethenes}

\author{
Ye, Jiahai* Ye, Wenfang Xiao, Chengtao Chen, Yu Wang, Guangpu \\ Zhang, Wenchao \\ (School of Chemical Engineering, Nanjing University of Science and Technology, Nanjing 210094)
}

\begin{abstract}
A series of $\beta$-formyl-boron-dipyrromethenes (BODIPYs) 2 and $\beta$-formyl-aza-BODIPYs 4 were synthesized from tetramethyl-BODIPYs 1 and tetraaryl-aza-BODIPYs 3 respectively via the Vilsmeier-Haack reaction using $(\mathrm{COCl})_{2}$ and DMF as the precursors efficiently. The Vilsmeier-Haack reaction was carried out smoothly under room temperature or $50{ }^{\circ} \mathrm{C}$ for BODIPYs or aza-BODIPYs respectively to give the $\beta$-formyl products in good yield. The advantage of this new method is the using of commercially available chemical and the less pollution.
\end{abstract}

Keywords BODIPY; aza-BODIPY; $\beta$-formylation; Vilsmeier-Haack reaction

氟硼吡咯(简称 BODIPY), 是一类具有非常优异的 光化学物理性能的有机小分子荧光染料. 此类化合物由 于具有较高的摩尔消光系数、很高的苂光量子产率、高 光物理稳定性和对周围环境的低敏感性等特性, 因而被 广泛用作激光染料 ${ }^{[1]}$ 、化学传感器 ${ }^{[2,3]}$ 、荧光开关 ${ }^{[4]}$ 、荧

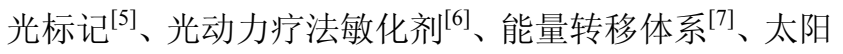
能电池敏化剂 ${ }^{[8]}$ 等. 近年来, 在氟硼吡咯母核上的官能 化, 尤其是不同位置连接上共轭结构使其具有独特物理 化学性能, 越来越受到重视 ${ }^{[9]}$. 其中, 氟硼吡咯的 $\beta$-甲 酰化是其中有价值的共轭官能化手段之一. 到目前为 止, $\beta$-甲酰氟硼吡咯的有效合成方法是 Jiao 等 ${ }^{[10]}$ 利用 Vilsmeier-Haack 反应实现的. 该反应中所用 VilsmeierHaack 试剂是由 $\mathrm{POCl}_{3}$ 和 $\mathrm{DMF}$ 在反应溶液中生成并直 接与 BODIPY 进行下一步反应. 由于 $\mathrm{POCl}_{3}$ 是剧毒化学 药品, 且属于国家管控的危险品, 此外, 反应废液中也 含有磷成分, 所以这些缺点在一定程度上影响了该方法 的应用.
基于我们在氟嗍吡咯母核官能化研究方面的兴 趣 ${ }^{[11]}$, 在本文中, 我们报道一种氟嗍吡咯 $\beta$-甲酰化的有 效新方法. 该方法利用草酰氯取代 $\mathrm{POCl}_{3}$ 与 $\mathrm{DMF}$ 在反 应溶液中生成 Vilsmeier-Haack 试剂, 再与 BODIPY 进行 反应，最后水解得到单取代 $\beta$-甲酰氟硼吡咯.

\section{1 结果与讨论}

\section{1 氟磁吡咯和氮杂氟嗍吡咯的 $\beta$-甲酰化}

Vilsmeier-Haack 试剂除了可以来自 $\mathrm{POCl}_{3}$-DMF 体 系, 还可以通过磺酰氯或草酰氯和 DMF 在反应溶液中 生成. 利用 $\mathrm{POCl}_{3}$ 或磺酰氯都有一个缺点, 就是反应残 液中分别具有磷或硫污染, 所以我们选择草酰氯-DMF 体系作为 Vilsmeier-Haack 试剂前体应用于氟硼吡咯的 $\beta$-甲酰化. 我们选择 8-苯基氟嗍吡咯(1a)作为底物用于 反应条件优化. 首先, 在冰水浴下将草酰氯和 DMF 溶 解在溶剂中制得 Vilsmeier-Haack 试剂, 再将该试剂缓 慢滴入反应底物 $1 \mathrm{a}$ 的溶液中并使其在一定温度下摚拌

* E-mail: yjhnjunjust@sina.com

Received April 20,2012; revised May 9, 2012; published online May 11, 2012. 